\title{
Barriers to Meaningful Involvement in AIDS Service Organizations in Three Canadian Maritime Provinces
}

\author{
Steven Michael Ross (Correspondence) \\ Thompson Rivers University, Canada \\ E-mail: stross@tru.ca \\ Lynne Duffy \\ University of New Brunswick, Canada \\ E-mail: lduffy@unb.ca
}

Leslie Jeffrey

University of New Brunswick, Canada

E-mail: ljeffrey@unb.ca

Donna Bulman

University of New Brunswick, Canada

E-mail: dbulman@unb.ca

Marni Amirault

Canadian Aboriginal AIDS Network

E-mail:marnia@caan.ca

Received: June 19, 2015 Accepted: October 11, 2015 Published: October 19, 2015

doi:10.5296/ijsw.v2i2.8031 URL: http://dx.doi.org/10.5296/ijsw.v2i2.8031 


\begin{abstract}
A three-year, community-based descriptive study examined how meaningful involvement in AIDS Service Organizations (ASOs) is conceptualized and experienced in three Canadian Maritime provinces that are considered rural areas. This paper focuses on one aspect of the research, namely the barriers to meaningful involvement in ASOs. Thirty-five participants were interviewed who self-identified as current or past clients of an ASO and were living with, or engaging in, at-risk behaviors for HIV/AIDS. Photovoice, a qualitative Community-Based Research (CBR) strategy, was also used with a small sample because marginalized populations that are traditionally difficult to recruit for interviews have embraced this method due to its oral-based and interactive design. The contribution to the field of knowledge about barriers to meaningful involvement is organized around three main themes: (1) stigma, a major negative influence, is particularly powerful due to the nature of social structures in rural communities; (2) readiness for meaningful involvement, where poor health status or the desire to lead a normal life can significantly impact an individual's involvement, and (3) characteristics of the ASO environment that are critical in determining the degree, if any, of meaningful involvement.
\end{abstract}

Keywords: ASOs, PHA, Stigma, Meaningful involvement, Community-based research, Photovoice; rural

\title{
1. Introduction
}

The Paris declaration, which was signed by the Canadian government in 1994, acknowledged the "Greater Involvement of Persons Living with HIV/AIDS" (GIPA) principle. The GIPA principle is significant in that it supports a greater involvement of people living with HIV at all levels and "stimulate(s) the creation of supportive political, legal, and societal environments" (International Council of AIDS Service Organizations, 1996, p. 5). Although past interpretations of GIPA have been consistent with "greater" involvement, recent discourse suggests GIPA to reflect more "meaningful" involvement, often referred to as MIPA. Numerous authors have described meaningful involvement as a collaborative, participatory, and consultative process of engagement among partners; one that promotes choice and information sharing (Fischer et al., 2007; Fischer \& Neale, 2008; Poulton, 1999). Despite the notion that meaningful involvement among people living with HIV/AIDS (PHA) or at-risk for HIV/AIDS is advantageous to both AIDS service organizations (ASOs) and service users respectively, recent literature indicates ongoing issues of poor participation among PHAs in ASOs, particularly in rural regions.

The majority of research to date about GIPA has been conducted in large urban centers and where many ASOs have implemented successful strategies to ensure meaningful involvement of PHAs. Unfortunately, these urban successes have not translated well into rural settings, primarily due to inattention to rural peoples' unique needs, diversity, and context. Constraints to GIPA are magnified in rural regions where there is no critical mass of service users and where stigmatization is a significant barrier. The operationalization of GIPA may be additionally challenged by difficulties in accessing and engaging further marginalized sub-groups, such as Aboriginal peoples and drug users. 
In this paper, we present one component (barriers to meaningful involvement) from a three-year qualitative study, which intended to: 1) contribute to the understanding of barriers that limit meaningful involvement of PHAs in ASOs in rural regions of Maritime Canada, and 2) provide insight to ASOs, policy makers, and PHAs about ways in which these barriers can be addressed to improve participation.

\section{Background}

The Maritime Provinces, located on the eastern seaboard of Canada and populated in primarily rural settings (60\%), include New Brunswick (NB), Prince Edward Island (PEI) and Nova Scotia (NS) (Public Health Agency of Canada, 2006).

The ASOs in the Maritimes face a number of unique challenges that are not typically experienced by ASOs in larger urban areas of Canada. For example, ASOs in the Maritimes, which are limited in number, frequently provide services: (a) with limited resources which require staff and program sharing to achieve goals, (b) to PHAs in a large catchment areas, (c) to at-risk persons, such as through needle exchanges, without provincial funding, and (d) to transient clientele.

\section{Literature Review}

Two bodies of literature that inform this paper are 1) the GIPA/MIPA principles, and 2) barriers to meaningful involvement within ASOs.

\subsection{GIPA/MIPA Principles}

GIPA/MIPA has been defined and understood in a variety of ways within the literature (Stephens, 2004; Travers, et al., 2008), however the core idea is the commitment to ensuring that the voices of PHAs are heard (White, 2001) and that human rights are respected (Ontario AIDS Network, 2011). GIPA/MIPA is often considered a model of best practice in local, national, and international organizations that respond to the HIV/AIDS epidemic (Stephens, 2004; UNAIDS 1999, 2004). GIPA may be described as either a grass roots movement or a more managed HIV/AIDS public health strategy (Stephens, 2004). Recently people have begun to use the term MIPA instead of GIPA in order to stress the need for not only greater involvement but also involvement that is meaningful to both individuals and organizations (Collins et al., 2007).

The GIPA/MIPA movement is widely accepted worldwide as contributing greatly to the health and welfare of PHAs. However, it has also been described as "a classed, raced, and gendered process" (Grabill, 2000, p. 40). GIPA/MIPA has also been critiqued as difficult to operationalize or measure (Roy \& Cain, 2001), tokenistic (Asia Pacific Network of People Living with HIV/AIDS, 2004), elitist (Cain et al. 2013), and poorly defined in either a policy or legal context (Stephens, 2004). General literature about GIPA is available from many ASOs, however, little research about GIPA has been carried out in an academic context (Bravo, Edwards, Rollnick, \& Elwyn, 2010). Current research suggests that in rural areas people may be reluctant to get involved in ASOs (Cain et al., 2013; Maxwell, Aggleton, \& Warwick, 2008) and that staff from ASO's have a significant role in fostering MIPA (Paterson, Ross, \& Gaudet, 2014).

\subsection{Barriers to Meaningful Involvement with ASOs}


Roy and Cain (2001) conducted a large national study using an open-ended questionnaire in 65 organizations with a focus on PHA involvement in ASOs. They suggested a number of significant barriers to meaningful involvement in an ASO, which include: (a) receiving an HIV positive diagnosis is secondary to challenging negative stereotypes and stigma, particularly within rural areas, (b) women finding it problematic to be open about their HIV status as they worry this may result in childcare issues, (c) ASOs being unable to provide adequate benefits for PHAs, (d) health concerns related to working/volunteering within stressful environments, (e) not having appropriate and timely transportation, and (f) challenging professional-client boundary issues (Roy \& Cain, 2001).

A Canadian study with a number of focus groups found that good health can be a barrier to meaningful involvement in ASOs as many PHAs work during the day when opportunities for involvement may be present (Cain et al., 2013). Interestingly, their earlier work suggested poor health might reduce participation. Cain et al. also found that the professionalization of services and decreased activism within the community had a negative impact on meaningful involvement.

Maxwell, Aggleton, and Warwick (2008) conducted group discussions with 38 PHAs and six HIV professionals in three areas of England. They found that lack of resources, inadequate procedures for providing feedback, insufficient clarity about the purpose of consultation, unsuitable structures for encouraging meaningful engagement, and concern over the group representativeness of those involved, were all significant in interfering with meaningful involvement.

Travers et al. (2008) surveyed and interviewed senior managers from ASOs in Ontario about barriers and facilitators to PHAs being involved in Community-Based Research (CBR). Findings suggested that HIV related stigma, health challenges, lack of capacity, distrust, other priorities, lived experience not being valued, limited mentoring opportunities, and insufficient financial compensation all contributed to low PHA involvement in the research.

Recent criminalization of HIV in Canada may cause people to be reluctant to discuss their HIV status and become involved in the HIV/AIDS movement (Mykahalovskiy \& Betteridge, 2012) and this may have a long-term influence on the principles of GIPA/MIPA.

This literature review has identified that implementing GIPA principles is a complex process and that there is a scant literature available relating these findings to rural areas in eastern Canada. This paper helps to address this gap in the literature.

\section{Methodology}

This research project was carried out using CBR that has been defined as "a collaborative approach to research that equitably involves all partners in the research process and recognizes the unique strengths that each brings" (Canadian Institute of Health Research, 2013, para. 30.). Consistent with CBR, our research team was made up of HIV positive people, those at risk of acquiring HIV/AIDS (self-identified), staff of community-based organizations, activists, and academics. Four universities (Thompson Rivers University, University of New Brunswick, Saint Thomas University, and Dalhousie University) granted ethics approval. 
The research design entailed a staged and mixed qualitative approach to address the complex and multidimensional issue of meaningful involvement. Results from the interviews and a photovoice component relating to barriers are presented.

\subsection{Interviews}

In order to have a wide range of participants representing different perspectives and agendas we invited people from three groups: 1) those who were HIV positive or who self-identified as at risk of acquiring HIV (identified as our population of interest [POI]), 2) service providers, and 3) policy makers.

Thirty-five persons (26 males, 9 females) from the first group agreed to participate. The majority (26/35) identified as HIV-positive, 21 identified as "straight, " eleven as "gay," and three said they were "bisexual." Ages ranged from 22 to 67 years with a mean of 41 years. Over three quarters indicated they were educated at high school or above.

Ten service providers were interviewed, with the majority being from Nova Scotia and New Brunswick. These individuals had a wide range of experience within organizations. Some had worked as support workers, as outreach workers, and in needle exchange programs. Six policy makers participated representing board members, researchers, and other individuals with varied experience in both the non-profit and for-profit sector.

Given that CBR includes capacity building, PHAs were offered skills training as research assistants in a two-day workshop and subsequently carried out the individual interviews that lasted between 90-120 minutes. Participants were asked open-ended questions about their understanding and experiences of meaningful involvement in an ASO and what initially motivated them to become involved. All interviews were tape recorded and transcribed verbatim.

A thematic analysis was completed. Two members of the research team developed an initial coding scheme that was later refined as the analysis progressed. All members of the team participated in coding the data. This helped to ensure that both inductive and deductive approaches were included. Everyone agreed on the selection of the final themes and the data was double-checked to ensure no forcing of data into categories occurred.

\subsection{Photovoice}

Photovoice is a qualitative, CBR strategy in which participants take photographs of the phenomenon under study (Wang, 1999). Foundations of this method include: (a) Freirianinspired problem posing and group dialogue leading to greater understanding of the topic and areas for change, (b) feminist theory to address gender inequality and oppression; (c) documentary photography, and (d) health promotion principles (Wang et al., 1998).

We chose photovoice because marginalized populations that are traditionally difficult to recruit for interviews (e.g., users of drugs, Aboriginal people) have embraced this method worldwide due to its oral-based and interactive design (Gold, 2004; Strack, Magill, \& McDonagh, 2004; Ti, Tzemis, \& Buxton, 2012) and we intended for the resulting photographs to provide a visual and powerful supplement to the discussion paper generated from the interview data.

The photovoice component occurred with a small number of ASO volunteers in a more remote part of one Maritime province. We selected this area because of the higher incidence 


\section{Macrothink}

of people experiencing particular challenges in engaging in the work of ASOs. Staff of the ASO recruited a convenience sample of participants from their service users and volunteers.

A training session was held so participants could learn about the project goals and photovoice process. Unfortunately, only three of the initial 11 people trained completed the project, reflecting possibly the recruitment strategies and the particular health challenges that included addictions. Those who were committed found the process both educational and empowering. Their first assignment was to: "Take pictures of people, places, or things that show what meaningful involvement in your ASO is like for you." The resulting photographs included positive or negative experiences and aspects that hindered or enabled involvement. The two subsequent assignments, each about a month apart, included looking for: (a) gaps in what had been collected, (b) what still needed to be said, and (c) how involvement could be made more meaningful.

In photovoice the participants, facilitated by the academic researcher, carry out analysis. The analysis process (Table 1) was explained to participants during the training and a large wall chart with the five guiding questions was posted during the meetings.

All discussions were audiotaped, transcribed as soon as possible by a professional transcriber, and later reviewed by the academic researcher and a community partner for further emerging issues and themes around meaningful involvement.

Table 1. Three-step photovoice analysis

A. Selecting: Participants choose two or more of their most significant pictures. (In turn these were projected onto a wall for everyone to see)

B. Contextualizing: Participants describe the meaning of the pictures guided by a Freirean-based critical dialogue. In this study the following modified process was used:

1) Describe your picture (Initial description)

2) How is this important to your life? (Deeper, personal meaning)

3) Why does this happen? (Root causes)

4) What needs to change? (Action)

5) Who should be involved in this change? (The person who owned the photograph began with steps 1 and 2 with other group members often joining the discussion in steps 3 to 5)

C: Codifying: Identifying issues or themes emerging from the dialogue

\section{Results}

The barriers to involvement are organized under three thematic areas, which include: (a) stigma, (b) readiness for meaningful involvement, and (c) characteristics of the ASO.

\subsection{The Role of Stigma in Rural Areas}

The most commonly identified barrier to ASO involvement was stigma. Stigma and its impacts have been widely discussed in the AIDS literature frequently applying Goffman's definition as a "discrediting" attribute that significantly reduces the status of the person marked by it (Goffman, 1963; Parker \& Aggleton, 2003). Importantly, Parker and Aggleton 
(2003) have pointed out that stigma is more than a "thing" or an "attitude"; it is a social process "linked to the reproduction of inequality and exclusion." (p. 17). Not surprisingly then, stigma negatively affects many areas of life including treatment, social and family relations, legal status, job opportunities, and housing options. The negative impacts have led others to note its role as a key barrier to meaningful involvement, particularly in smaller and rural areas (Roy \& Cain 2001; Ti, Tzemis, \& Buxton, 2012; Travers et al., 2008).

We noted three important aspects of the operation of stigma as a barrier in the Maritime context, which include: (a) the density of social networks which intensifies the speed and impact of stigma, (b) the reinforcement of the multiple layers of stigma because of the diversity of populations served by singular ASOs, and (c) the difficulties of being outspoken (and therefore countering stigma) in a small town or rural setting.

\subsubsection{Density of Social Networks in the Rural Setting}

The density of social networks that characterize rural areas like the Maritimes profoundly affects the impact of stigma. Here people, and/or their families, are likely to have lived in a particular town for a long time and have: (a) extensive social networks, (b) family networks that are intensified by the presence of several generations and branches in the same town (extended family may all live within a fairly restricted geographic area), and (c) social circles that easily overlap (for example, employers or prospective employers may know other family members via various social connections e.g. group membership, neighborhood). These connections intensify both the likelihood of identification (being "seen"); the speed of communication (news/gossip spreads quickly and easily) and the impact of stigma (family members and job opportunities can be affected). Even if people have left for larger centers to live a part of their lives, once they return home the social networks can close in very quickly. Therefore, being "outed" has the potential for quick and far-reaching ramifications.

In our interviews, stigma was clearly the primary barrier to becoming involved in ASOs in any way. While walking into an ASO in small towns could lead to stigma, participants noted that parking in front of the building is also risky as cars can be connected to their owners, often by sight. The ease of identification in communities with dense social networks makes the fear of stigma that much greater. As one respondent said:

When the [ASO] first started in PLACE, people were afraid to come in and be seen coming into the ASO because you were tagged right away as having AIDS and [that's] not a good thing. Not in this small community, not a good thing at all .... If I'm seen going in there often, I'm bound to be seen by somebody that knows me and right away then you're tagged as having HIV.

Being "seen" can have profound implications. Given the size of the communities the chances are higher that you will be recognized, or gossiped about, by family, friends, employers or even prospective employers. A number of interviewees talked about the effect on their careers and families if they were identified with the ASO. "I have to maintain my anonymity to succeed in this community... I wouldn't get ahead socially or career-wise if I was outed.

Not only might one be identified by being seen near or in the ASO, the intimacy of news coverage in small towns increases the risk of identification. The local paper often covers what could be considered mundane and unremarkable events elsewhere, and the paper is read by 
most people or its contents reported to them. One respondent related that just going to a meeting can quickly become a public outing and cause a family rift.

My wife and my son were at a meeting at the ASO in TOWN and somebody from our newspaper was there ... and then my son's picture was in the paper and his grandfather called my wife and told her if she was to be involved in the ASO anymore she was not to ever have contact with his family again.

And it is not only at the ASO where one has to worry about being identified. The closeness of families and communities also multiplies risks to confidentiality. One respondent told how medical staff had spoken to him about another's status and how he feared that his own confidentiality could be breeched. "You have to go into small little hospitals and do your blood work and, myself, I have a lot of relatives that work in the hospital and I'm trying not to let them know..." As well, some photovoice participants expressed concern about breaks in confidentiality by volunteers and peers at the ASO.

\subsubsection{Multiple and Interacting Stigmas}

HIV, addiction, and sexuality stigmas are mutually reinforcing. Parker and Aggleton (2003) have suggested that researchers pay closer attention to the "intensifying interaction between multiple forms of inequality and exclusion" in order to "untangle the complex webs of meaning and power that are at work in HIV and AIDS-related stigma" (p. 19). While multiple and interacting stigmas are common elsewhere, in the Maritimes each of these stigmas is reinforced and intensified by the density of social networks.

As some of our respondents pointed out, fear of being labeled as gay, not just HIV positive, can mean that people also fear becoming involved in an ASO.

I would say the stigma of HIV is associated with being gay. No wonder they (straight people) don't come out ... they start being called faggot and all this sort of stuff. I can see why they don't say anything.

We noted that women often fear being labeled a sex worker with its own attendant problems, which like anti-gay stigma can result in harassment, marginalization, and even violence. And, with limited gay rights organizations, there are few voices that are readily available in the media or public discussion to counter these views. There is only one dedicated sex-worker support organization in the entire Maritime region. One woman related;

I was just newly diagnosed and I felt dirty and disgusting... because I lived in a bubble. I didn't know anything about the illness and everything I knew was negative about it. so...to have to deal with that and then have people assume that I was like a prostitute or a drug user on top of that.... It was hard.

\subsubsection{Being Outspoken in a Small Town}

It is important to remember, however, that individuals can take an empowerment approach to stigma (Corrigan \& Watson, 2002; Shih, 2004). Correcting misperceptions and the desire to fight stigma can be powerful motivators for involvement (Paterson, Ross, \& Gaudet, 2013).

Overcoming stigma may depend in part on where people are in their own lives. Some participants took measures to counteract the possibility of being recognized in a smaller area by working with ASOs in larger centers outside their own towns, while others simply took the leap of "coming out" no matter what the consequences. Certainly many of our respondents, 
despite the risks, were committed to the idea of involvement because of the importance of people speaking from experience:

The best way I can say it ... HIV/AIDS on the streets is a real bad dirty nasty thing.

Nobody wants to be within a hundred feet near it let alone hear it. And that's what stops a lot of people like myself ... being shunned, being looked down on, being scented out. But you know like myself once again knowledge is power. The public needs very badly to be informed and by somebody firsthand is the best way in my eyes.

Being outspoken on any issue, especially a controversial one, can carry a heavy price in a small community. There is a certain degree of "going along for the sake of getting along" that can be helpful in bringing people together to support each other in difficult times. However, one result is the tendency of not "rocking the boat" and of being careful in criticizing people or situations because, once again, the tightly knit social circles mean one could easily be talking about someone's friend or family member. Speaking out under these conditions can be viewed as "rude" and socially unacceptable. It takes a great deal of courage, then, to step out and speak up. Not only can one quickly become "the face" of an issue because there are so few people willing to speak out, even peers may turn against you in the face of such social pressure.

Consequently, there is a price to be paid for being "out" which has a multiplier effect on the strength of stigma as a barrier to involvement. Even when someone overcomes their own barriers and takes the risk of becoming involved, they can lose other supports. One respondent who is out as a PHA and active in the ASO explained that even among PHAs he can be ostracized because his being out puts his PHA friends at risk of being identified. He described a painful incident where he dropped off Christmas items for an ASO client, a long-time acquaintance, who became extremely angered by the possibility of being identified by receiving the package. So even within the gay or PHA community "We're shunned because people don't want to associate with us because we're very public about it."

\subsection{Readiness for Meaningful Involvement}

A second theme from the study focused on readiness for meaningful involvement. Being able to stand up to stigma depends heavily on one's physical and mental readiness to take this on. Health status, both positive and negative, was identified as a significant barrier to meaningful involvement in ASOs.

\subsubsection{Health Challenges}

A number of respondents identified that readiness was challenged by a variety of physical and mental health issues. Several participants suggested that physical health and associated symptoms of HIV and hepatitis C significantly impacted readiness to make meaningful contributions to an ASO.

Since I've been diagnosed with HIV I've been in the hospital a few times on account of the medications plus the HIV. I have heart problems and well that's the major thing ....My skin is terrible. Dermatitis.

Some suggested that mental health challenges complicated their readiness. One noted: "I have mental health issues that were as a result of drug abuse [and they] caused my levels in 
my brain to not function properly and [I] was put on lithium carbonate...(for my) Bi-polar Intermittent Explosive Disorder."

Health conditions require various appointments with doctors, nurses, counselors, and pharmacists that take time and energy and inhibit involvement in an ASO. While physical and mental health are barriers commonly raised in the literature (Cain et al., 2013; Travers et al., 2008) and certainly not unique to rural regions such as the Maritimes, it is important to note that the more limited availability of medical services and difficulty accessing services in this region may make this barrier more difficult to overcome.

\subsubsection{Improved Health}

Improved health outcomes of an HIV/AIDS diagnosis are to be celebrated, while recognizing this also impacts meaningful involvement. Participants noted that as their health improves they are too busy with work and other family and social commitments to be involved with the ASO or they do not want reminders of their status that comes with ASO involvement.

Years ago we all wanted to be involved because we were all given a death sentence and we were just biding time until we died. And we all had time on our hands. As years went on we got healthier and things changed and now we're living more of a normal life ... and it's really hard to find time to do this stuff.

Later we will also see how those who were diagnosed earlier and now doing well find the changes in ASO functioning to be unacceptable.

\subsection{The ASO Environment}

A critical component of meaningful or greater involvement is the environment of the local ASO. When it is welcoming and inviting participants feel comfortable to spend time there and commit to a variety of activities to support the work. When it is perceived as not being welcoming people stay away. The following themes emerged from the interviews and the photovoice discussions: (a) conflict, (b) underutilization, (d) accessibility, and (d) staffing and service issues. Many of these are also recognized as barriers in the broader literature on meaningful participation (Cain, 2002), although the rural context affects the ability of ASOs to avoid or respond to these issues.

\subsubsection{Conflict}

Conflict was a common theme for many of the participants. People found themselves in arguments over different aspects of the work. "I don't work there, but I volunteer... and I've seen it done and then everyone gets in a big argument and then it's not a nice place to be." Differing agendas can result in conflict and, as this participant noted, HIV/AIDS and related issues of care and treatment are already sensitive topics and people may have unresolved personal issues and differing agendas that can interfere with team work.

Then you've got a lot of long-term survivors that...to be honest, through my own experience, that have some...issues from twenty years ago that have they never really dealt with... and they bring that to the table and that causes friction as well. It's the politics of very high emotional illness in itself. 
Another participant spoke about the intimidation that can occur with strong personalities, especially for new volunteers.

What I see there's a lot of strong...people with strong voices, strong opinions and they sometimes tend to overrun situations. So someone that's, you know, new in the scene would be intimidated by that. They would probably feel, well, if that person feels that strong about it then I'd better not give my opinion.

Although intimidation may occur in both rural and urban ASOs, it is particularly difficult to challenge in rural areas due to the density of social networks. In the photovoice study none of the participants had been or were presently board members and felt the need to be careful with staff interactions.

You have to caution how far you go around here because...let's say...you wanted to have something done, say about the way somebody is doing their job, they take that very personal. You have, it's like you have to walk on tiptoes. I don't know, like I can't explain fully, but it's just like you kind of have to watch what you're doing around here because you don't want to offend people.

\subsubsection{Underutilization}

Participants expressed frustration that their talents were not used effectively. One noted, "I' $m$ very articulate and I'm very disciplined, but for some reason they won't put me out into the community because I speak what is my truth and they [the community] don't want to hear that." A member of the photovoice group explained her picture of a Do Not Enter sign. "I feel like some things only certain people can do, like... don't go there. Like there's stuff here that I find only certain people can do.... "It limits what you can and can't do."

Several talked about wanting to be "invited" into more involvement, that they see others doing things they would like to do, but no one ever asks them. Low self-esteem, lack of confidence, and shyness, prevent some from making a request or even filling out an application. At times it depends who is present at the ASO, so if a person is not physically there, an opportunity for involvement is missed. "They don't go out of their way to make phone calls to try to track you down."

\subsubsection{ASO Accessibility}

Accessibility involves many things such as physical aspects of the person, available resources for transport, and emotional or cultural safety. For some, physical accessibility made involvement difficult or impossible when the ASO was too far away from where they lived or they lacked affordable transport. Others had concerns around limited hours of opening, and how they are staffed, with many saying that ASOs need to be better known.

\subsubsection{Hours and Schedules}

While participants in the photovoice study mainly lived in the downtown area and were closer to the ASO, some of their challenges to involvement related more to lack of time due to childcare, appointments, and other responsibilities. Some found the regular office hours of the ASO were limiting when one has a full time job and family obligations.

Some people are just busy. Most days various organizations are only open during office hours. Like for example, for me, if I wanted to go to [the ASO in town] right now, I'm 
working. But even times when I'm not working I have a child and I have a family and it's only open nine to four.

For some the often-harsh winters in eastern Canada, in combination with limited or scarce public transportation, limit their ability to move around and therefore impact their ability to become involved as they felt "stranded in the winter months."

\subsubsection{Staffing and Service Issues}

Having a mix of both male and female workers is seen as important to meet the needs to both genders. "I really can't sit down and talk to a female about certain issues and when your support worker is a female and you're male sometimes you just don't want to talk to them about certain things."

Another barrier to involvement is the quick turnover of staff resulting in clients and volunteers having to rebuild trusting relationships. "I usually think it's professionals who sign one year contracts and after their one year is up usually they leave and somebody else comes." This person also felt that having life experience (being HIV positive or a history of drug use) is possibly more important in the job than having a degree, and that might result in greater commitment. He also recognized the challenges associated with this option.

What kind of people run AIDS centers?.... They have diplomas or degrees.... First of all I'm not aware of too many people, positive people, that have...like a professional background where they would be able to, you know, run that place; an ASO. ...I mean from what I've seen most people who are positive are...kind of on the edge of society.

Another participant discussed the benefits of seeing someone with the same diagnosis. "It's a lot easier, it was a lot more comfortable working with and volunteering with people that were also positive because there's actually no judgment there at all. And you don't really have to hide anything from anybody." Another also noted that ASOs might better meet the needs if people with the lived experience are involved in decision-making. " [ASOs] need to find out really what our needs are and not what people say our needs are who never had a day of discrimination...."

5.3.6 Changing Patterns in HIV Programs and Priorities

Those who have been HIV positive for many years noticed a major decline in services and in the attention paid to HIV/AIDS in general that results in fewer volunteers.

Things change and sometimes I think it's not for the good. And I just...got angry... and I had to walk away... I'm back again but with a clear head starting over. Sometimes I just feel, I don't know, it was more personable years ago. So, I don't think I'd want to be a newly diagnosed person now. To be honest with you I found years ago there was more, it seemed... there was more to offer, more help than there is today.... I know there's only so much funding and stuff like that. I get it... I just didn't feel like I was part of a team for a while.

As mentioned earlier, the health situation for those with a positive diagnosis, is much improved from earlier years, yet there are continuing challenges especially around the attention paid to the illness. Many of the long term survivors are frustrated and no longer participate. 
We're not all dying like we were ... the whole disease has really changed, it's not like you are diagnosed and you die eight months later anymore.... Our health may not be the best, but it's a hell of a lot better than what it was. So that pressure is gone. ...the funding being cut, money is so hard to get; so everyone is just fighting to get what they can for whatever project that they can. I don't think there is much of coming together anymore. It's basically, what group are we going to focus on this year to get funding for?"

Former volunteers find that the roles they had in the past are no longer wanted and they are not sure how to be involved in new ways.

The clients we have now don't want a buddy. They've got family. They've got friends.... So it's often a little disappointing to the volunteers that come in. [The clients] are very independent you know, self-fulfilling, still working, whatever. People really don't want somebody in their life that's to remind them they're a person living with HIV.

Another noted that present ASO activities don't represent him (e.g. Pride parades) or his skills, the ASO is no longer doing hospital visits, and today's organization is more "clinical." Another noted the loss of an advocacy role.

\section{Discussion}

Stigma, in many forms, is seen to be one of the largest barriers to ASO involvement for PHAs and arguably, for many PHA supporters in the Maritimes. "Stigmatization is also used by dominant groups to legitimize and perpetuate inequalities and ... can help us understand how it is that those who are stigmatized and discriminated against so often accept and even internalize, the stigma to which they are subjected," (Parker \& Aggleton, p. 10, 2003). One way to combat HIV-related stigma in its many forms is to normalize the illness and dispel the myths that surround HIV; for example, the idea that all people who are HIV positive are homosexual or intravenous drug users. This could be done through enhanced and comprehensive education at multiple levels of society. The intensity and impact of stigma in rural areas means that even greater effort is needed to support anti-stigma efforts by ASOs and their allies, such as gay rights organizations.

We heard above that some PHAs are interested in sharing their stories and speaking to youth about their HIV status. Perhaps if more individuals who are ready and interested in sharing their stories are mentored and provided with skills for public speaking, stigma around HIV can be greatly reduced. Because of people's fear of being identified and labeled, ASOs could increase their use of intercommunity exchanges for education. Clearly from the discussion above, many communities would benefit from education on even the most basic information about HIV - virus transmission, for example. One photovoice participant stated:

Like I even found out my brother was gay and I didn't take that very well. And the first place I came to was here [ASO] and they talked to me about it and I came like to grips with reality.. To accept him. ... I didn't understand, but I came here and they helped me understand. So this is a really good place.

Understanding helped this individual work through the fears, misunderstandings, and the stigma that she held about homosexuality. 


\subsection{ASOs}

In their paper about PHA involvement in community-based HIV/AIDS organizations across Canada, Roy and Cain (2001) state that PHAs “...often saw community-based AIDS organizations as slow to respond to changing needs. Users often saw their local groups as increasingly bureaucratic, and they criticized workers for not making the immediate and practical needs of PWA enough of a priority." (p. 422). Many of the PHAs in this study who accessed ASOs in their respective provinces echo the observations made by these authors. Efforts should be made by ASO management and staff to lessen the appearance of bureaucracy in an effort to create a more relaxed and inviting environment for PHAs. Paying closer attention to the needs of clientele and inviting them to give feedback on the existing organization may result in a safer space where much needed and more valuable and applicable services can be accessed.

For many PHAs in this study, even with considerable explanation and discussion, understanding the term 'meaningful involvement' was difficult. The women who participated in the photovoice project, for example, did not readily understand the term. Initially, when asked to represent meaningful involvement through pictures, these participants returned with photos that often represented personal stories about their life journeys.

Additionally, what one person may identify as a meaningful way to engage in an ASO may not be seen as meaningful to another. For some, being available to the ASO for tasks such as helping with mail-outs and Food Bank activities may be seen as meaningful, while others may seek out positions that have them acting in a more official capacity with considerable responsibility; becoming a board member or performing speaking and education outreach engagements, for example. ASOs could take inventory of tasks they are over-burdened with and look for interested individuals to help carry out the work.

One thing is clear from the above discussion; the landscape of HIV and AIDS has changed from the 1980s when HIV/AIDS first became known. Today, someone who receives an HIVdiagnosis is no longer being served a death sentence in tandem with their diagnosis. With the advent of anti-retrovirals in 1996, HIV is increasingly being seen and treated as a long-term, chronic disease. The effects of this change in status from terminal to chronic has many implications for the involvement of PHAs in ASOs due to the fact that many HIV positive people are living longer, healthier, and more 'normalized' lives. For several individuals who were interviewed, this means that other things in their lives take priority over their HIV status. Work and family life, for example, may make involvement in an ASO difficult.

Better access to ASOs by offering services outside of traditional Monday to Friday, 9 AM - 5 PM business hours may also go a long way in attracting more clientele. Better advertising of the kinds of services each organization offers may be another tactic, as we saw above. Getting the ASO on the radar of local television, newspapers, and radio stations to highlight some of the more positive aspects of their work may assist in bringing new clients and volunteers to the organizations. At the same time increased media coverage could work towards combatting the existing stigma in more rural communities, and may go a long way towards normalization of HIV and AIDS as well. 


\section{Recommendations to ASOs}

- Increase outreach and education about HIV and AIDS in the community among the general population with an aim to decreasing the multi-layered stigma and misunderstanding that exists in smaller communities around HIV

- Advertise ASO services as broadly as possible

- House ASOs in more discreet locations to allow those afraid of being targeted by stigma to engage with the ASO

- Allow for more flexible hours at the ASO - many PHAs need to access services and programs at the ASO during hours that are outside of the 'normal' 9 - 5 business day

- Increase the number and capacity of the individuals who access the ASO to perform some of the duties that help the ASO function

- Build the capacity of ASO volunteers who are interested in public speaking, serving on the ASO board etc. Mentor PHAs in talking to community groups about their lived experiences

- Run programs designed to empower PHAs. One example is training PHAs as Peer Research Associates/Assistants (PRAs) in community-based projects

- Offer a friendly and welcoming environment. This may mean balancing professionalism and warmth by creating a more relaxed setting that accommodates people 'dropping in', for example

- Where possible aim for a gender balance in the ASO staff

- Proactively recruit PHAs as volunteers.

\section{Conclusion}

Through this research we have confirmed that stigma is a major and negative influence on meaningful involvement in ASOs. This stigma is particularly powerful due to the nature of the social structures in rural communities. Another important influence is the ever-changing health status of those living HIV/AIDS. At times, meaningful involvement is difficult because of poor health. Yet, when health is improved, demands of every-day life and the desire to lead a normal life impact the ability and willingness to volunteer. Thirdly, the ASO environment can itself be a barrier. While recognizing the many challenges faced by more rural ASOs (underfunding, understaffing, and overburdened mandates), there are small, but effective changes in ASO daily operations that could enhance and increase meaningful involvement of PHAs and other potential volunteers. Future research could usefully investigate the impact of changing laws and policies (e.g. new federal funding formulas, broadening of mandates beyond HIV, and criminalization of HIV/AIDS) on ASO's ability to make these changes and address these challenges.

\section{Acknowledgements}

This study was funded by the Canadian Institutes of Health Research (CIHR): grant number 200911 CBG

\section{References}

Asia Pacific Network of People Living with HIV/AIDS. (2004).Position Paper 2-GIPA. http://www.gnpplus.net/regions/files/APN_GIPA_position.com 


\section{Macrothink}

International Journal of Social Work ISSN 2332-7278 2015, Vol. 2, No. 2

Bravo, P., Edwards, A., Rollnick, S., \& Elwyn, G. (2010). Not just another chronic illness. The dilemma of people living with HIV - a support worker's perspective. HIV Nursing, 12(2). 6.

Cain, R. (2002). Devoting Ourselves, Devouring Each Other: Tensions in Community-Based AIDS Work. Journal of Progressive Human Services, 13(1). 93-113. http://dx.doi.org/10.1300/J059v13n01_06

Cain, R., Collins, E., Bereket, T., George, C., Jackson, R., Li, A., et al. (2013). Challenges to involvement of people living with HIV in community-based HIV/AIDS organizations in Ontario, Canada. AIDS Care: Psychological and socio-medical aspects of HIV/AIDS, 26(2), 263-266. http://dx.doi.org/10.1080/09540121.2013.803015

Canadian Institute of Health Research. (2013). About the HIV/AIDS community-based research program. http://www.cihr-irsc.gc.ca/e/40943.html\#d1

Collins, E., Cain, R., Bereket, T., Chen, Y., Cleverly, S., George, C. et al., (2007). Living and serving II: The involvement of people living with HIV in the community AIDS movement in Ontario. http://www.ohtn.on.ca/documents/publications/living_serving_report_april07.pdf

Corrigan, P., \& Watson, C. (2002). The paradox of self-stigma and mental illness. Clinical Psychology: Science and Practice, 9(1), 35-53. http://dx.doi.org/10.1093/clipsy.9.1.35

Fischer, J., Jenkins, N., Bloor, M., Neale, J., \& Berney, L. (2007). Drug user involvement in treatment decisions. Glasgow: Joseph Rowntree Foundation.

Fischer, J., \& Neale, J. (2008). Involving drug users in treatment decisions: An exploration of potential problems. Drugs: Education, Prevention and Policy, 15(2), 161-175. http://dx.doi.org/10.1080/09687630701391604

Goffman, E. (1963). Stigma: Notes on the management of a spoiled identity. New York: Simon \& Schuster.

Gold, S. (2004). Using photography in studies of immigrant communities. American Behavioral Scientist, 47(12), 1551e1572. http://dx.doi.org/10.1177/0002764204266237

Grabill, J. (2000). Shaping local HIV/AIDS service policy through activist research: The problem of client involvement. Technical Communication Quarterly, 9(1), 29-50. http://dx.doi.org/10.1080/10572250009364684

International Council of AIDS Service Organizations. (1996). Declaration of the Paris AIDS summit. The legacy of the Paris Summit. Paris: Author.

Maxwell, C., Aggleton, P., \& Warwick, I. (2008). Involving HIV-positive people in policy and service development: Recent experiences in England. AIDS Care, 20(1), 72-79. http://dx.doi.org/10.1080/09540120701449120

Mykhalovskiy, E., \& Betterridge, G. (2012). Who? What? Where? When? And with what consequences? An analysis of criminal cases of HIV non-disclosure in Canada. Canadian Journal of Law \& Society, 27(1), 31-54. http://dx.doi.org/10.3138/cjls.27.1.031

Ontario AIDS Network (2011). Living and serving: GIPA engagement guide and framework for Ontario ASO's.

Parker, R., \& Aggleton, P. (2003). HIV and AIDS-related stigma and discrimination: A conceptual framework and implications for action. Social Science \& Medicine, 57(1), 13-24. 
http://dx.doi.org/10.1016/S0277-9536(02)00304-0

Paterson, B., Ross, S., \& Gaudet, T. (2014). Motives for meaningful involvement in AIDS Service Organizations. AIDS Car, 26(5), 582-586. http://dx.doi.org/10.1080/09540121.2013.843771

Poulton, B. C. (1999). User involvement in identifying health needs and shaping and evaluating services: Is it being realized? Journal of Advanced Nursing, 30(6), 1289-1296. http://dx.doi.org/10.1046/j.1365-2648.1999.01224.x

Public Health Agency of Canada. (2006). Canada's rural communities: Understanding rural health and its determinants. Ottawa: Author.

Roy, C., \& Cain, R. (2001). The involvement of people living with HIV/AIDS in community-based organizations: Contributions and constraints. AIDS Care, 13(4), 421-432. http://dx.doi.org/10.1080/09540120120057950

Shih, M. (2004). Positive stigma: Examining resilience and empowerment in overcoming stigma. Annals of the American Academy of Political and Social Science, 591(1), 175-185. http://dx.doi.org/10.1177/0002716203260099

Stephens, D. (2004). Out of the shadows: The involvement of people living with HIV/AIDS in policy. POLICY Working Paper Series No. 14, Washington: The Futures Group International.

Strack, R., Magill, C., \& McDonagh, K. (2004). "Engaging youth through Photovoice." Health Promotion Practice, 5(1), 49-58. http://dx.doi.org/10.1177/1524839903258015

Ti, L., Tzemis, D., \& Buxton, J. (2012) Engaging people who use drugs in policy and program development: A review of the literature. Substance Abuse Treatment, Prevention, and Policy, 7(47), 1-9. http://dx.doi.org/10.1186/1747-597x-7-47

Travers, R., Wilson, M., Flicker, S., Guta, A., Bereket, T., ... Rourke, S. B. (2008). The greater involvement of people living with AIDS principle: Theory versus practice in Ontario's HIV/AIDS community-based research sector. AIDS Care: Psychological and Socio-medical Aspects of AIDS/HIV, 20(6), 615-624. http://dx.doi.org/10.1080/09540120701661690

UNAIDS. (1999). From principle to practice: Greater involvement of people living with or affected by HIV/AIDS (GIPA). Geneva: UNAIDS.

UNAIDS. (2004). Report on the global HIV/AIDS epidemic: $4^{\text {th }}$ global report. Geneva: UNAIDS.

Wang, C. (1999). Photovoice: A participatory action research strategy applied to women's health. Journal of Women's Health, 8(2), 185-192. http://dx.doi.org/10.1089/jwh.1999.8.185

Wang, C. C., Yi, W. K., Tao, Z. W., \& Carovano, K. (1998). Photovoice as a participatory health promotion strategy. Health Promotion International, 13, 75-86. http://dx.doi.org/10.1093/heapro/13.1.75

White, C. (2001). Beyond professional harm reduction: The empowerment of multiply-marginalized illicit drug users to engage in politics of solidarity towards ending the war on illicit drug users. Drug and Alcohol Review, 20(4), 449-458. http://dx.doi.org/10.1080/09595230120092742 


\section{Macrothink

\section{Copyright Disclaimer}

Copyright reserved by the author(s).

This article is an open-access article distributed under the terms and conditions of the Creative Commons Attribution license (http://creativecommons.org/licenses/by/3.0/). 